\title{
CRESCIMENTO RADICULAR E NUTRIÇÃO DA CEVADA EM FUNÇÃO DA CALAGEM E APLICAÇÃO DE GESSO ${ }^{(1)}$
}

\author{
EDUARDO FÁVERO CAIRES ${ }^{(2,4)}$; ITACIR CESAR FELDHAUS ${ }^{(3)}$; \\ JULIUS BLUM ${ }^{(3)}$ \\ RESUMO
}

A calagem superficial ou incorporada e a aplicação de gesso no solo levam a modificações químicas no perfil que podem influenciar o crescimento de raízes das culturas anuais. O crescimento radicular e a nutrição da cevada, cv. BR 2 (sensível ao $\mathrm{Al}$ ), foram estudados em função da aplicação de calcário dolomítico (sem calcário e 4,5 tha ${ }^{-1}$ de calcário na superfície ou incorporado) e doses de gesso $(0,3,6$ e 9 t.ha $^{-1}$ ), em LATOSSOLO VERMELHO Distrófico textura argilosa, em Ponta Grossa (PR). O delineamento experimental adotado foi o de blocos ao acaso em esquema de parcela subdividida, com três repetições. Os tratamentos de calagem (parcelas) e as doses de gesso (subparcelas) foram aplicados na instalação do sistema plantio direto, em 1998. Avaliaram-se as alterações nos atributos químicos do solo e no crescimento de raízes de cevada no inverno de 1999, após o cultivo de soja. A calagem, na superfície ou incorporada e a aplicação de gesso não influenciaram significativamente o crescimento radicular da cevada, embora o gesso tenha proporcionado melhor distribuição relativa de raízes em profundidade, principalmente quando associado à calagem. Em condições de déficit hídrico severo, não houve limitação no crescimento radicular da cevada, em profundidade, para o teor de Ca trocável de $6 \mathrm{mmol}_{\mathrm{c}} \cdot \mathrm{dm}^{-3}$ e a saturação por $\mathrm{Al}$ de $35 \%$. A incorporação de calcário melhorou a nutrição de $\mathrm{N} \mathrm{e}$ $\mathrm{K}$ da cevada, mas a produção não foi influenciada pela correção da acidez do solo por meio da calagem na superfície ou com incorporação, certamente devido à prolongada estiagem no período de florescimento da cultura, o que limitou a produção de grãos. A aplicação de gesso melhorou a absorção de $\mathrm{N}, \mathrm{P}, \mathrm{K}, \mathrm{Ca}$ e S pela cevada, em condições de deficiência hídrica, proporcionando acréscimos na produção de grãos, em decorrência do aumento de Ca trocável, da relação $\mathrm{Ca} / \mathrm{Mg}$ e do $\mathrm{S}^{-\mathrm{SO}_{4}}{ }^{2-}$ disponível no solo.

Palavras-chave: acidez, subsolo, sistema radicular, cálcio, enxofre, sistema plantio direto.

\section{ABSTRACT \\ BARLEY NUTRITION AND ROOT GROWTH AS AFFECTED BY LIME AND GYPSUM APPLICATIONS}

Root growth can be affected by chemical modifications in the soil profile due to lime and gypsum applications. A field trial was carried out on a dystrophic Clay Rhodic Hapludox at Ponta Grossa, State of Paraná, Brazil, aiming at evaluating lime and gypsum effects on root growth and plant chemical traits of barley, cv. BR 2 (Al susceptible). A randomized complete block design was used, with three replications, in a split-plot layout. The main plots received dolomitic limestone treatments (no lime and 4.5 tha $^{-1}$ of lime-on the surface or incorporated into the soil) and the subplots, the rates of gypsum $\left(0,3,6\right.$ and 9 t.ha $\left.^{-1}\right)$, applied in the installation of a no-tillage system, in 1998. Barley was grown during the 1999 winter season, after the soybean crop. Liming (whether surface applied or incorporated into

(1) Recebido para publicação em 20 de abril e aceito em 7 de novembro de 2001.

(2) Departamento de Ciência do Solo e Engenharia Agrícola, Universidade Estadual de Ponta Grossa (UEPG), $84010-790$ Ponta Grossa (PR). E-mail: efcaires@uepg.br

$\left({ }^{3}\right)$ Aluno do Curso de Agronomia, UEPG. Bolsista do PIBIC/CNPq.

$\left({ }^{4}\right)$ Com bolsa de produtividade em pesquisa do CNPq. 
the soil), and gypsum rates did not significantly affected barley root growth, although gypsum provided better root relative distribution in the soil profile, mainly when associated to liming. Under severe water stress conditions there was no limitation to barley root growth in depth (for $6 \mathrm{mmol}_{\mathrm{c}} \cdot \mathrm{dm}^{-3}$ exchangeable $\mathrm{Ca}$ and $35 \% \mathrm{Al}$ saturation). Lime incorporation improved the plant nutrition as to $\mathrm{N}$ and $\mathrm{K}$, but liming treatments did not affect grain yields-these were limited by the prolonged water deficit during flowering stage. However, gypsum increased N, P, K, Ca and S plant levels, even under water stress conditions, with significant effects on grain yields, due to increases in the exchangeable $\mathrm{Ca}$, $\mathrm{Ca} / \mathrm{Mg}$ relationships and $\mathrm{S}_{-} \mathrm{SO}_{4}{ }^{2-}$ levels available in the soil.

Key words: acidity, subsoil, root system, calcium, sulphur, no-tillage system.

\section{INTRODUÇÃO}

Nos últimos anos, tem aumentado o interesse pela busca de alternativas para a implantação de culturas no sistema plantio direto, em áreas novas, sem proporcionar revolvimento do solo. As vantagens desse procedimento estão relacionadas à manutenção das características químicas e estruturais do solo, ao maior controle da erosão e à economia com as operações de incorporação de calcário e preparo do solo. No entanto, caso a acidez do solo não seja adequadamente corrigida, o crescimento radicular e a nutrição das plantas podem ser comprometidos. O problema é tanto mais grave quanto maior for a deficiência de água para as culturas (Olmos e CAMARGO, 1976).

O Al em concentrações tóxicas causa redução na taxa de crescimento de raízes, interferindo na absorção de água e nutrientes pelas plantas (CLARKSON, 1967; MCCORMick e Borden, 1972). O Ca exerce influência no crescimento radicular, mas os limites do nutriente para garantir o crescimento de raízes não estão bem definidos. Ritchey et al. (1982) mostraram que 1,0 a $1,5 \mathrm{mmol}_{\mathrm{c}} \cdot \mathrm{dm}^{-3}$ de Ca normalizavam o crescimento de raízes. Outros trabalhos, porém, demonstram que a soja (Rosolem et al., 1995), o amendoim (CAIRES e Rosolem, 1991) e o milho (RosolEm et al., 1994) respondem em crescimento de raízes a teores bem mais elevados de $\mathrm{Ca}$, da ordem de $15 \mathrm{mmol}_{\mathrm{C}} \cdot \mathrm{dm}^{-3}$.

Por meio da calagem é possível corrigir a acidez e alterar os teores de Ca em camadas superficiais e do subsolo, tanto com a incorporação de calcário, em sistema convencional de preparo do solo (CAIRES e Rosolem, 1993; QuAGGIO et al., 1993), como também com a sua aplicação na superfície, em sistema plantio direto (Oliveira e Pavan, 1996; Caires et al., 2000). Porém, apenas aplicações de calcário não parecem suficientes para promover grande melhoria química do ambiente radicular no subsolo, pela movimentação de bases trocáveis. Utiliza-se o gesso agrícola a fim de aumentar o suprimento de Ca e reduzir a toxicidade de Al no subsolo (SUMNER, 1995), resultando em melhor ambiente ao crescimento de raízes em profundidade.

A calagem superficial ou incorporada e a aplicação de gesso no solo levam a modificações químicas no perfil que podem influenciar o crescimento de raízes das culturas anuais. A cevada tem mostrado aumentos consideráveis na produção de grãos com o calcário aplicado na superfície do solo ou incorporado, em solos ácidos manejados no sistema plantio direto (PöttKer e Ben, 1998).

O presente trabalho foi realizado com o objetivo de avaliar o crescimento do sistema radicular e a nutrição mineral de uma cultivar de cevada sensível ao Al, em função de alterações nos atributos químicos do solo proporcionadas pela calagem, na superfície ou com incorporação, e pela aplicação de doses de gesso, na instalação do sistema plantio direto.

\section{MATERIAL E MÉTODOS}

O experimento foi realizado no município de Ponta Grossa (PR), Fazenda Regina, em um LATOSSOLO VERMELHO Distrófico textura argilosa, até então utilizado para pastagem. Os resultados de análises químicas iniciais do solo estão apresentados no quadro 1.

O delineamento experimental adotado foi o de blocos ao acaso em esquema de parcelas subdivididas, com três repetições. Nas parcelas, aplicaram-se três tratamentos de calcário dolomítico com 89\% de PRNT: testemunha (sem calcário); calcário na superfície $\left(4,5\right.$ t.ha $\left.{ }^{-1}\right)$ e calcário incorporado $\left(4,5\right.$ t.ha $\left.{ }^{-1}\right)$. A dose de calcário utilizada foi definida de acordo com o método da elevação da saturação por bases para $70 \%$, em amostra de solo coletada na profundidade de 0-20 cm. Nas subparcelas, aplicaram-se, em superfície, quatro doses de gesso: 0, 3, 6 e 9 t.ha ${ }^{-1}$. As aplicações de calcário dolomítico e de gesso agrícola foram realizadas, respectivamente, em julho e em outubro de 1998. O calcário, no tratamento com incorporação, foi aplicado em duas etapas. A primeira constou da aplicação manual de metade da dose antes da aração com arado de discos, a $20 \mathrm{~cm}$ de profundidade. Na segunda etapa, aplicou-se o restante do calcário, manualmente, após a aração e pouco antes da gradagem, com grade niveladora. As áreas de cada parcela e subparcela foram, respectivamente, de 224 e $56 \mathrm{~m}^{2}$. 
Quadro 1. Resultados de análises químicas de amostras de solo, em diferentes profundidades, antes da instalação do experimento

\begin{tabular}{|c|c|c|c|c|c|c|c|c|c|c|}
\hline \multirow{2}{*}{$\begin{array}{l}\text { Profun- } \\
\text { didade }\end{array}$} & \multirow{2}{*}{$\begin{array}{c}\mathrm{pH} \mathrm{em} \\
\mathrm{CaCl}_{2}\end{array}$} & \multirow[b]{2}{*}{$\mathrm{H}+\mathrm{Al}$} & \multicolumn{4}{|c|}{ Cátions trocáveis } & \multirow{2}{*}{ P (Mehlich-1) } & \multirow{2}{*}{ C-orgânico } & \multirow{2}{*}{$\begin{array}{c}\text { Saturação } \\
\text { por } \mathrm{Al}^{3+}\end{array}$} & \multirow{2}{*}{$\begin{array}{l}\text { Saturação } \\
\text { por bases }\end{array}$} \\
\hline & & & $\mathrm{Al}^{3+}$ & $\mathrm{Ca}^{2+}$ & $\mathrm{Mg}^{2+}$ & $\mathrm{K}^{+}$ & & & & \\
\hline $\mathrm{cm}$ & & 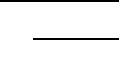 & $\mathrm{m}$ & $\mathrm{ol}_{\mathrm{C}} \cdot \mathrm{dm}$ & & $\overline{-}$ & $\mathrm{mg} \cdot \mathrm{dm}^{-3}$ & g.dm ${ }^{-3}$ & $\longrightarrow$ & $\overline{-}$ \\
\hline $0-20$ & 4,6 & 77,6 & 3 & 25 & 20 & 3,6 & 0,3 & 31 & 6 & 38 \\
\hline $20-40$ & 4,2 & 97,0 & 8 & 7 & 8 & 2,2 & 0,1 & 21 & 32 & 15 \\
\hline $40-60$ & 4,2 & 83,6 & 8 & 4 & 8 & 1,5 & 0,1 & 14 & 37 & 14 \\
\hline
\end{tabular}

A cevada BR 2, sensível ao alumínio (Minella et al., 1999), foi semeada em 4 de junho de 1999, após o cultivo de soja (1998/99), na densidade de 40 sementes por metro e espaçamento de $0,17 \mathrm{~m}$ entre as linhas. $\mathrm{Na}$ adubação de semeadura, utilizaram-se $28 \mathrm{~kg} \cdot \mathrm{ha}^{-1}$ de $\mathrm{N}$ e $92 \mathrm{~kg}$.ha ${ }^{-1}$ de $\mathrm{P}_{2} \mathrm{O}_{5}$, na forma de fosfato diamônico (DAP), e $45 \mathrm{~kg} \cdot \mathrm{ha}^{-1}$ de $\mathrm{N}$, na forma de uréia, em cobertura.

Coletaram-se amostras de solo antes da semeadura da cevada, correspondendo a 11 meses após a calagem e 8 após a aplicação de gesso. A precipitação pluvial ocorrida no período compreendido entre a aplicação de calcário e de gesso e a amostragem de solo foi, respectivamente, de 1.805 e $1.175 \mathrm{~mm}$. Retiraram-se, por meio de trado, 12 subamostras por subparcela para constituir uma amostra composta das camadas de 0-10 e 10-20 cm, e cinco subamostras para as camadas de $20-40$ e $40-60 \mathrm{~cm}$ de profundidade. Determinaram-se o $\mathrm{pH}$ e os teores de $\mathrm{H}+\mathrm{Al}, \mathrm{Al}^{3+}$, $\mathrm{Ca}^{2+}, \mathrm{Mg}^{2+}$ e K ${ }^{+}$, segundo PAVAN et al. (1992). Realizaram-se, também, análises de $\mathrm{S}_{-} \mathrm{SO}_{4}{ }^{2-}$, nas diferentes profundidades do solo, mediante extração pelo acetato de amônio a $0,5 \mathrm{~mol} . \mathrm{L}^{-1}$ em ácido acético a 0,25 mol. $L^{-1}$ e posterior determinação pelo método turbidimétrico, descrito por VITTI e SUZUKI (1978).

No início de florescimento da cultura, coletaramse amostras de folhas em 30 plantas de cada subparcela, retirando-se toda a parte aérea da primeira à quarta folha a partir do ápice das plantas. Essas amostras foram lavadas em água desionizada, colocadas para secar em estufa com circulação forçada de ar a $60{ }^{\circ} \mathrm{C}$, até atingirem massa constante, e posteriormente moídas. Analisaram-se os teores de N, P, K, Ca, $\mathrm{Mg}$ e $\mathrm{S}$ pelos métodos descritos em Malavolta et al. (1997).

As amostras de raízes foram coletadas na fase de espigamento da cultura, aos 96 dias após a semeadura, por meio de trado cilíndrico, em quatro profundidades $(0-10,10-20,20-40$ e $40-60 \mathrm{~cm})$, retirando-se seis subamostras, sendo três na linha de semeadura e três nas entrelinhas, para constituir uma amostra composta. As amostras, com 3,5 cm de diâmetro, foram tomadas ao acaso, nos tratamentos de calcário (sem calcário, calcário na superfície e calcário incorporado) e gesso (0 e 9 t.ha $\left.{ }^{-1}\right)$. Separaram-se as raízes do solo por dispersão em água, por meio de peneira de $0,5 \mathrm{~mm}$. O comprimento de raízes foi estimado pelo método de TENNANT (1975) e o raio médio e a superfície radicular, segundo HALLMARK e BARBER (1984). Nessa época, também coletou-se $1 \mathrm{~m}$ de linha contínua de plantas de cada subparcela, somente a parte aérea, para avaliar a produção de matéria seca e a absorção de nutrientes, determinando-se os teores de N, P, K, Ca, Mg e S, segundo Malavolta et al. (1997).

Durante o desenvolvimento da cevada, houve severo déficit hídrico no período de florescimento da cultura. A precipitação pluvial foi de 155, 109, 3, 111 e $77 \mathrm{~mm}$, respectivamente, nos meses de junho, julho, agosto, setembro e outubro de 1999. O balanço hídrico seqüencial decendial revelou um déficit hídrico de $30 \mathrm{~mm}$ durante todo o ciclo da cultura; $80 \%$ desse déficit $(24 \mathrm{~mm})$ ocorreu no período de florescimento das plantas.

Após a maturação, a cevada foi colhida e trilhada, determinando-se, então, a produção de grãos a 130 g.kg-1 de umidade. Colheram-se as 20 linhas centrais por $4 \mathrm{~m}$ de comprimento em cada subparcela, desprezando-se $2 \mathrm{~m}$ de cada extremidade.

Os resultados foram submetidos às análises da variância e de regressão. Na ausência de significância da interação calcário $x$ gesso sobre as variáveis estudadas, compararam-se os efeitos da calagem pelo teste de Tukey ao nível de $5 \%$ e do gesso por análises de regressão, utilizando-se as médias das observações. Adotou-se como critério para escolha do modelo a magnitude dos coeficientes de regressão significativos ao nível de $5 \%$.

\section{RESULTADOS E DISCUSSÃO}

As alterações na densidade de comprimento, superfície radicular e raio médio de raízes de cevada, nas quatro profundidades estudadas, em função dos tratamentos de calagem e aplicação de gesso (Quadro 2), não foram significativas pelo teste de Tukey ao nível de $5 \%$. O coeficiente de variação médio foi de 
$27 \%, 30 \%$ e $12 \%$, respectivamente, para densidade de comprimento, superfície e raio médio de raízes. Não foram encontradas relações significativas entre as características de crescimento de raízes e os atributos químicos do solo relacionados à acidez, em razão da profundidade. Isso significa que o crescimento radicular da cevada foi semelhante, independentemente das alterações químicas do solo proporcionadas pela calagem, realizada na superfície ou com incorporação, e aplicação de gesso. Apesar de os teores de Ca trocável serem suficientes e não existir $\mathrm{Al}$ trocável em teores tóxicos para o crescimento de raízes nas camadas superficiais do solo, no subsolo as condições químicas eram bem mais desfavoráveis ao crescimento radicular. Mesmo assim, a melhoria do subsolo ácido não resultou em maior enraizamento da planta, mostrando que o teor de Ca de $6 \mathrm{mmol}_{\mathrm{c} .} \cdot \mathrm{dm}^{-3}$ e a saturação por $\mathrm{Al}$ de $35 \%$ em profundidade $(40-60 \mathrm{~cm})$ não foram limitantes para o crescimento radicular da cevada. A calagem, na superfície ou com incorporação, proporcionou maior concentração do sistema radicular na camada superficial do solo $(0-10 \mathrm{~cm})$, e a aplicação de gesso contribuiu para melhorar a distribuição relativa de raízes em profundidade, principalmente quando se realizou a calagem.

A presença de Ca nas soluções em contato com as raízes é essencial para a sua sobrevivência, pois não há a translocação do nutriente da parte aérea para as porções novas das raízes em crescimento. A ausência de resposta do sistema radicular observada ao aumento de Ca nas camadas do subsolo (Quadro 2) deve estar relacionada aos valores extremamente baixos de limite crítico do nutriente para o crescimento de raízes (RitcheY et al., 1982). Cabe ressaltar que existem diferenças entre espécies e variedades de plantas, ocorrendo controle genético da eficiência das plantas na utilização de Ca (Clark, 1976 citado por RAIJ, 1988).

Diversos estudos indicam alta sensibilidade da cevada à atividade tóxica do $\mathrm{Al}$ (CAMERON et al., 1986; FOY, 1996; PÖTTKER e BEN, 1998). No presente trabalho, os teores de $\mathrm{Al}$ trocável não eram muito elevados, apesar da alta saturação por $\mathrm{Al}$ em profundidade (Quadro 2). Porém, em estudo realizado em colunas de solo, também não se verificou maior enraizamento da cevada mediante melhoria das condições de acidez em subsuperfície, em solo com teores de $\mathrm{Al}$ trocável e valores de saturação por $\mathrm{Al}$ bem mais elevados (WRIGHT et al., 1985).

ADAMs e MOORE (1983) verificaram que os teores de $\mathrm{Al}$ trocável, saturação por $\mathrm{Al}$ e $\mathrm{Al}$ na solução do solo não foram bons indicadores de crescimento de raízes em horizontes de subsolo ácido, pois a complexação do Al por compostos orgânicos solúveis pode reduzir
Quadro 2. Características de crescimento de raízes de cevada e atributos da fertilidade do solo, em diferentes profundidades, considerando os tratamentos de calagem, na ausência e na presença de gesso ( 0 ou 9 t.ha $^{-1}$ )

\begin{tabular}{|c|c|c|c|c|c|c|}
\hline \multirow{2}{*}{$\begin{array}{l}\text { Profun- } \\
\text { didade }\end{array}$} & \multicolumn{2}{|c|}{$\begin{array}{c}\text { Sem } \\
\text { calcário }\end{array}$} & \multicolumn{2}{|c|}{$\begin{array}{c}\text { Calcário na } \\
\text { superfície }\end{array}$} & \multicolumn{2}{|c|}{$\begin{array}{c}\text { Calcário } \\
\text { incorporado }\end{array}$} \\
\hline & $\begin{array}{l}\text { Sem } \\
\text { gesso }\end{array}$ & $\begin{array}{l}\text { Com } \\
\text { gesso }\end{array}$ & $\begin{array}{c}\text { Sem } \\
\text { gesso }\end{array}$ & $\begin{array}{l}\text { Com } \\
\text { gesso }\end{array}$ & $\begin{array}{l}\text { Sem } \\
\text { gesso }\end{array}$ & $\begin{array}{l}\text { Com } \\
\text { gesso }\end{array}$ \\
\hline & \multicolumn{6}{|c|}{ Densidade de raízes, $\mathrm{cm}_{\mathrm{cm}} \mathrm{cm}^{-3}$} \\
\hline $0-10$ & 2,58 & 2,28 & 3,01 & 2,04 & 3,85 & 2,85 \\
\hline $10-20$ & 0,72 & 0,50 & 0,52 & 0,56 & 0,50 & 0,59 \\
\hline $20-40$ & 0,36 & 0,34 & 0,32 & 0,38 & 0,36 & 0,32 \\
\hline \multirow[t]{2}{*}{$40-60$} & 0,30 & 0,28 & 0,22 & 0,23 & 0,23 & 0,27 \\
\hline & \multicolumn{6}{|c|}{ Superfície radicular, $\mathrm{cm}^{2} \cdot \mathrm{cm}^{-3}$} \\
\hline $0-10$ & 0,273 & 0,232 & 0,323 & 0,211 & 0,403 & 0,305 \\
\hline $10-20$ & 0,064 & 0,047 & 0,052 & 0,052 & 0,042 & 0,054 \\
\hline $20-40$ & 0,039 & 0,032 & 0,034 & 0,043 & 0,039 & 0,036 \\
\hline \multirow[t]{2}{*}{$40-60$} & 0,028 & 0,028 & 0,016 & 0,024 & 0,018 & 0,029 \\
\hline & \multicolumn{6}{|c|}{ Raio médio de raízes, $\mathrm{mm}$} \\
\hline $0-10$ & 0,17 & 0,16 & 0,17 & 0,17 & 0,17 & 0,16 \\
\hline $10-20$ & 0,14 & 0,15 & 0,16 & 0,15 & 0,13 & 0,15 \\
\hline $20-40$ & 0,17 & 0,15 & 0,17 & 0,19 & 0,17 & 0,18 \\
\hline \multirow[t]{2}{*}{$40-60$} & 0,15 & 0,15 & 0,15 & 0,17 & 0,17 & 0,13 \\
\hline & \multicolumn{6}{|c|}{ Distribuição relativa de raízes, \% } \\
\hline $0-10$ & 55 & 54 & 65 & 53 & 69 & 60 \\
\hline $10-20$ & 16 & 14 & 12 & 16 & 9 & 14 \\
\hline $20-40$ & 16 & 17 & 15 & 19 & 13 & 14 \\
\hline \multirow[t]{2}{*}{$40-60$} & 13 & 15 & 8 & 12 & 9 & 12 \\
\hline & \multicolumn{6}{|c|}{$\mathrm{pH}, \mathrm{CaCl}_{2}$ 0,01 mol.. ${ }^{-1}$} \\
\hline $0-10$ & 4,7 & 4,8 & 5,3 & 5,1 & 5,5 & 5,5 \\
\hline $10-20$ & 4,4 & 4,5 & 4,6 & 4,6 & 4,8 & 4,8 \\
\hline $20-40$ & 4,2 & 4,5 & 4,4 & 4,7 & 4,6 & 4,7 \\
\hline \multirow[t]{2}{*}{$40-60$} & 4,3 & 4,5 & 4,3 & 4,6 & 4,5 & 4,6 \\
\hline & \multicolumn{6}{|c|}{ Cálcio trocável, $\mathrm{mmol}_{\mathrm{c} .} \cdot \mathrm{dm}^{-3}$} \\
\hline $0-10$ & 31 & 66 & 35 & 69 & 41 & 84 \\
\hline $10-20$ & 16 & 30 & 18 & 31 & 20 & 32 \\
\hline $20-40$ & 11 & 29 & 16 & 38 & 23 & 39 \\
\hline \multirow[t]{2}{*}{$40-60$} & 6 & 13 & 6 & 20 & 10 & 21 \\
\hline & \multicolumn{6}{|c|}{ Alumínio trocável, $\mathrm{mmol}_{\mathrm{c} \cdot \mathrm{dm}} \mathrm{dm}^{-3}$} \\
\hline $0-10$ & 2 & 2 & 0 & 0 & 0 & 0 \\
\hline $10-20$ & 4 & 4 & 3 & 3 & 2 & 1 \\
\hline $20-40$ & 7 & 4 & 5 & 2 & 3 & 2 \\
\hline \multirow[t]{2}{*}{$40-60$} & 6 & 5 & 6 & 4 & 4 & 3 \\
\hline & \multicolumn{6}{|c|}{ Saturação por alumínio, \% } \\
\hline $0-10$ & 4 & 2 & 0 & 0 & 0 & 0 \\
\hline $10-20$ & 12 & 8 & 8 & 6 & 6 & 3 \\
\hline $20-40$ & 22 & 10 & 14 & 5 & 7 & 4 \\
\hline $40-60$ & 34 & 19 & 35 & 10 & 16 & 9 \\
\hline
\end{tabular}


a sua toxicidade. De acordo com Hoyt e TURNER (1975), o crescimento da cevada em um solo ácido foi bastante melhorado em decorrência da complexação de Al pela adição de grande quantidade de matéria orgânica.

WRIGTH et al. (1985) obtiveram aumento significativo no crescimento de raízes de cevada com a aplicação de adubo orgânico, admitindo a possibilidade de que a melhoria do crescimento radicular tenha sido causada pela complexação de Al por compostos orgânicos solúveis. Observa-se, também, em sistemas em que resíduos vegetais são mantidos na superfície do

$$
\mathrm{Mg} \text { trocável, } \mathrm{mmol}_{\mathrm{c}} \cdot \mathrm{dm}^{-3}
$$
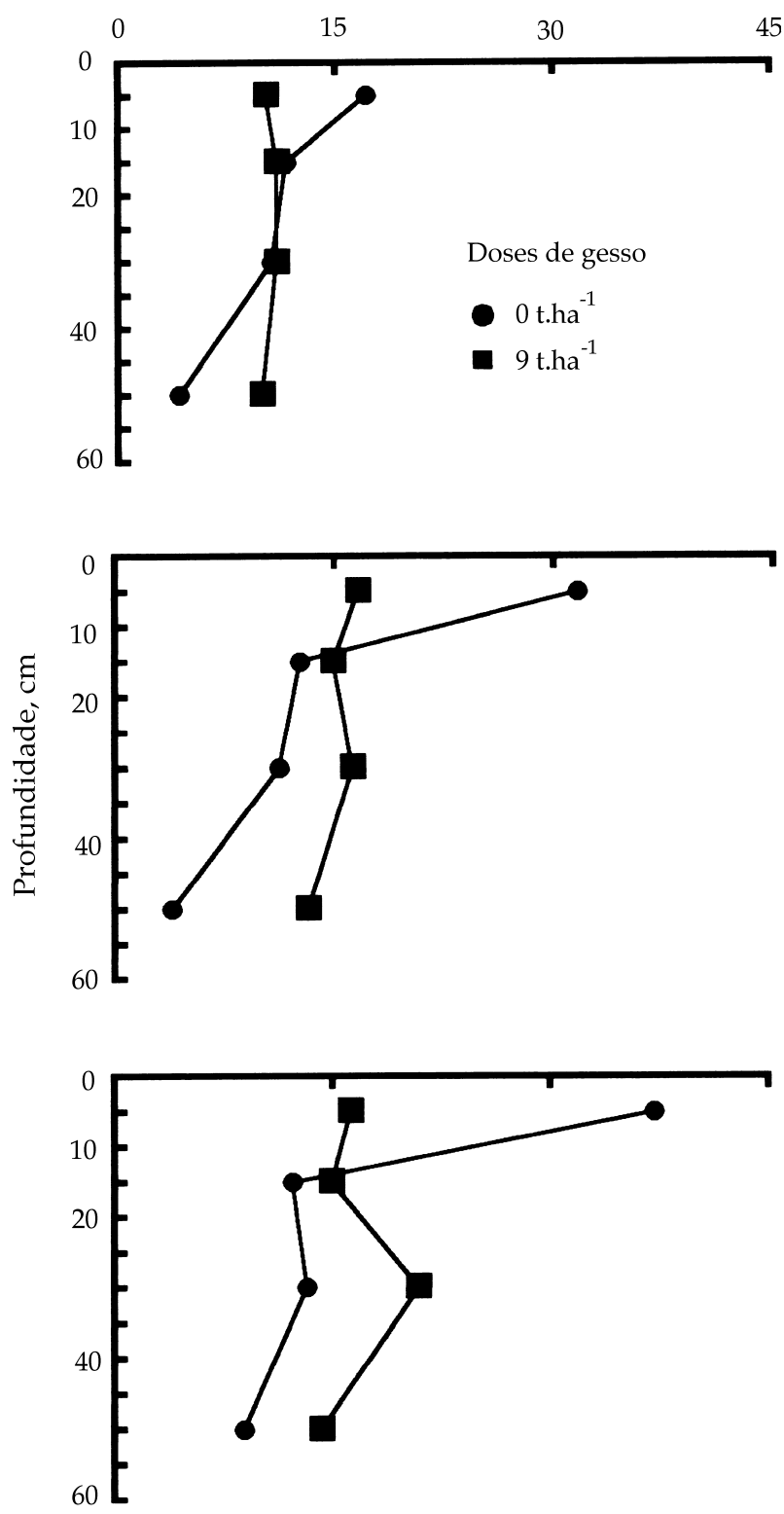

solo (plantio direto) redução da atividade tóxica do $\mathrm{Al}$ (SAlET et al., 1996; MiYAZAWA et al., 1996; Franchini et al., 1999) em decorrência de sua complexação orgânica por compostos solúveis presentes nos restos das plantas.

Os efeitos dos tratamentos de calagem e aplicação de gesso sobre os teores de Mg e K trocáveis do solo, nas quatro profundidades estudadas, estão apresentados na figura 1 . Houve aumento dos teores de $\mathrm{Mg}$ trocável na camada superficial do solo $(0-10 \mathrm{~cm})$ mediante a aplicação de calcário dolomítico, mas o gesso causou movimentação do $\mathrm{Mg}^{2+}$ das camadas superfi-

(A)

K trocável, $\mathrm{mmol}_{\mathrm{c}} \cdot \mathrm{dm}^{-3}$

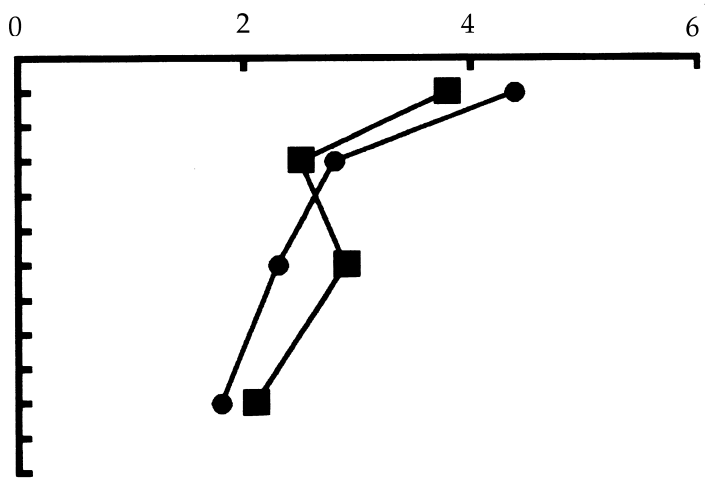

(B)

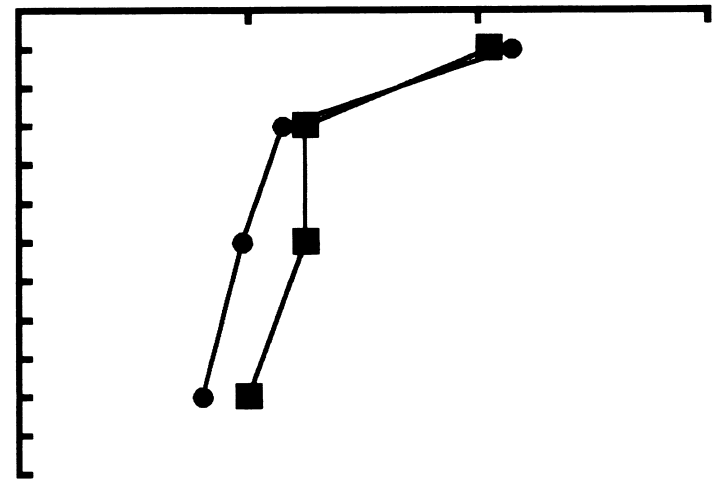

(C)

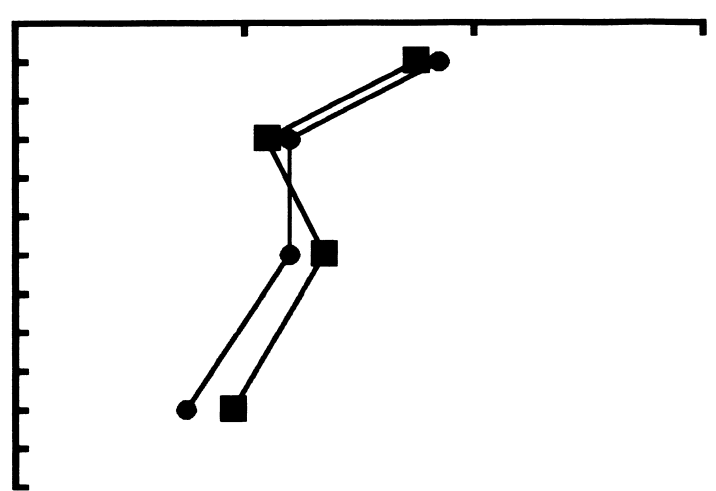

Figura 1. Efeito de doses de gesso $\left(0\right.$ e 9 t.ha $\left.{ }^{-1}\right)$ sobre os teores de $\mathrm{Mg}$ e K trocáveis no solo, em diferentes profundidades, considerando os tratamentos de calagem: sem calcário (A), calcário na superfície (B) e calcário incorporado (C). 
ciais para o subsolo, proporcional à elevação dos teores do nutriente pela calagem na superfície e incorporada. As equações de regressão dos teores de $\mathrm{Mg}$ trocável na camada de $0-10 \mathrm{~cm}\left(\hat{Y}\right.$, em $\left.\mathrm{mmol}_{\mathrm{c} \cdot} \cdot \mathrm{dm}^{-3}\right)$, em função de doses de gesso $\left(x\right.$, em t.ha $\left.^{-1}\right)$, foram: $\hat{Y}=18,13-0,84 x\left(R^{2}=0,88^{*}\right), \hat{Y}=29,52-1,74 x$ $\left(R^{2}=0,83^{* *}\right)$ e $\hat{Y}=34,53-2,27 x\left(R^{2}=0,90^{* *}\right)$ para os tratamentos sem calcário, calcário na superfície e calcário incorporado respectivamente. Esses resultados demonstram claramente que a movimentação do $\mathrm{Mg}^{2+}$ é mais acentuada na presença de maiores teores do nutriente no solo. Resultados semelhantes foram observados por CAIRES et al. (1998). Ressalta-se que a lixiviação de $\mathrm{Mg}$ trocável tem sido resposta freqüente nos estudos com aplicação de gesso em solos (Carvalho et al., 1986; Syed-Omar e Sumner, 1991; Oliveira e Pavan, 1996). No caso do K trocável, seus teores não foram influenciados significativamente pela calagem na superfície ou com incorporação, e a movimentação do nutriente proporcionada pela aplicação de gesso foi extremamente menor. Embora a lixiviação do K trocável pelo uso de gesso possa ocorrer em função do tipo de solo (Sousa e RITCHEY, 1986; SUMNER, 1995), essa movimentação tem sido muito pequena em sistema plantio direto (CAIREs et al., 1998).

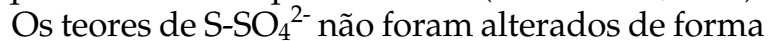
significativa pelos tratamentos de calagem, encontrando-se, nas quatro profundidades estudadas, concentrações médias de 11,8 $(0-10 \mathrm{~cm}), 7,6(10-20 \mathrm{~cm})$, 7,2 $(20-40 \mathrm{~cm})$ e 6,0 $(40-60 \mathrm{~cm}) \mathrm{mg} \cdot \mathrm{dm}^{-3}$. Percebe-se que os teores de sulfato decrescem com a profundidade, o que, certamente, decorre da ausência de adubações anteriores com fertilizantes que contêm enxofre. A aplicação de doses de gesso proporcionou aumento significativo e linear nos teores de $\mathrm{S}^{-\mathrm{SO}_{4}}{ }^{2-}$, nas quatro profundidades estudadas. O aumento médio desses teores, para cada tonelada de gesso aplicada, foi de $16,5,17,2,15,1$ e $10,6 \mathrm{mg} \cdot \mathrm{dm}^{-3}$, respectivamente, nas profundidades de 0-10, 10-20, 20-40 e 40-60 cm. Nota-se que o $\mathrm{S}_{-} \mathrm{SO}_{4}{ }^{2-}$ do gesso se distribuiu regularmente pelo perfil do solo, ao invés de ficar acumulado em alguma camada, concordando com os resultados obtidos por SOUSA e RitCHEY (1986). Ressalta-se que essa avaliação foi realizada 8 meses após a aplicação de gesso; nesse período, ocorreu precipitação pluvial de $1.175 \mathrm{~mm}$. Mesmo assim, o movimento de $\mathrm{S}_{-} \mathrm{SO}_{4}{ }^{2-}$ foi mais rápido que o de $\mathrm{Ca}^{2+}$, comportamento típico de solos com predominância de carga líquida negativa (CAMARGO e RAIJ, 1989).

Os teores de $\mathrm{N}$ nas folhas de cevada foram influenciados pelos tratamentos de calagem e doses de gesso (Figura 2). Nota-se que, na ausência de aplicação de gesso, houve maior concentração de $\mathrm{N}$ nas folhas quando o calcário foi incorporado. A aplicação de doses de gesso aumentou a concentração foliar de $\mathrm{N}$, com resposta linear na ausência de calcário e quadrática para o calcário aplicado na superfície ou com incorporação. De acordo com as equações de regressão ajustadas, o maior teor de $\mathrm{N}$ nas folhas seria obtido com as doses de 9,0, 5,3 e 4,6 t.ha ${ }^{-1}$ de gesso, respectivamente, para os tratamentos sem calcário, calcário na superfície e calcário incorporado. Esses resultados mostram que o aumento na taxa de mineralização da matéria orgânica, em decorrência da incorporação de calcário, resulta em maior teor foliar de $\mathrm{N}$, e que o gesso é capaz de aumentar a concentração de $\mathrm{N}$ nas folhas, certamente pelo seu efeito favorável nos atributos químicos do subsolo relacionados à acidez. Dessa maneira, a calagem, associada à aplicação de gesso, aumenta o aproveitamento de N pela planta. Observou-se em outros trabalhos efeito favorável do gesso na absorção de N pelas culturas de milho (SouSA e Ritchey, 1986) e sorgo (RAIJ et al., 1988).

Os tratamentos de calagem não influenciaram as concentrações de $\mathrm{P}, \mathrm{K}, \mathrm{Ca}, \mathrm{Mg}$ e $\mathrm{S}$ nas folhas de cevada, enquanto as doses de gesso aumentaram os teores foliares de K, Ca e S (Quadro 3). Maior absorção de K com aplicação de gesso em um subsolo ácido e pobre em bases foi constatada por RAIJ et al. (1988). Aumento nos teores foliares de Ca e $S$ também tem sido observados em outros trabalhos (QUAGGIO et al.,

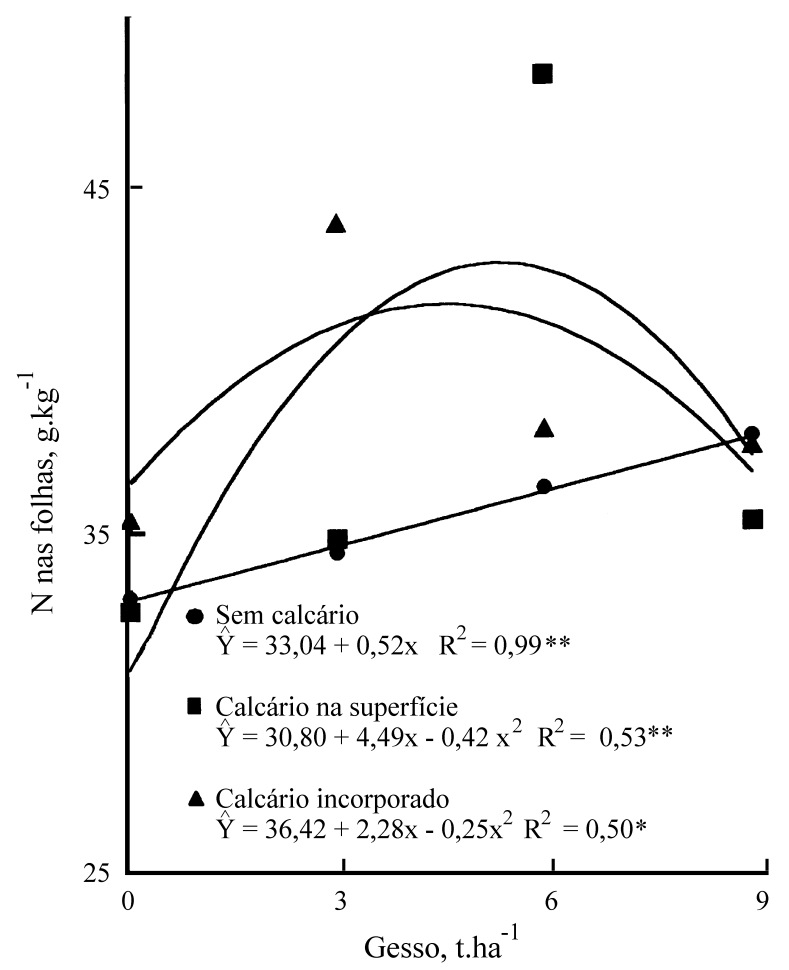

Figura 2. Concentração de nitrogênio nas folhas de cevada em função de doses de gesso, considerando os tratamentos de calagem. ${ }^{*}{ }^{* *}$ : Significativo a $5 \%$ e $1 \%$ respectivamente. 
1993; CAIRES et al., 1999), considerando que o gesso é excelente fonte desses dois nutrientes. A concentração de $\mathrm{Mg}$ nas folhas de cevada não foi influenciada significativamente pelos tratamentos de calcário e gesso, apesar das alterações nos teores de $\mathrm{Mg}$ trocável no solo proporcionadas pela calagem e aplicação de gesso (Figura 1).

A produção de matéria seca da parte aérea da cevada não foi alterada de forma significativa pelos tratamentos de calagem e doses de gesso; observou-se produção média de $8.990 \mathrm{~kg} \cdot \mathrm{ha}^{-1}$ de matéria seca na fase de espigamento da cultura aos 96 dias após a semeadura.

A calagem com incorporação apresentou aumento significativo somente para a absorção de $\mathrm{K}$. O déficit hídrico de $24 \mathrm{~mm}$, que ocorreu no período de florescimento da cultura, deve ter prejudicado os efeitos da calagem na absorção dos demais nutrientes. Houve maior absorção de N, P, K, Ca e S com a aplicação de doses de gesso (Quadro 4). Cabe ressaltar que esse aumento na absorção de nutrientes não é decorrente de modificações no crescimento radicular, embora a aplicação de gesso tenha causado melhoria na distribuição relativa de raízes em profundidade (Quadro 2). É mais provável que tais efeitos tenham ocorrido por alterações na atividade tóxica do $\mathrm{Al}$ e na disponibilidade de nutrientes no solo.

O aumento da absorção de $\mathrm{N}$ pelas doses de gesso demonstra os efeitos benéficos dessa aplicação em estimular a absorção do nutriente do subsolo (SousA e RitChEY, 1986; RAIJ et al., 1988). A maior absorção de
P, em função do gesso aplicado, deve ter sido conseqüência da presença de fósforo, considerado impureza, na composição do gesso agrícola. No caso de aplicações de doses elevadas, o fósforo contido no gesso agrícola pode ser importante na nutrição vegetal (RAIJ, 1988). O aumento da absorção de K com a calagem e aplicação de doses de gesso talvez esteja relacionado com o aumento nos teores de Ca trocável no solo, pois há liberação de $\mathrm{K}$ dos sítios de troca para a solução do solo, conforme relatado por NoGUEIRA e Mozeto (1990). O efeito do gesso no aumento da absorção de Ca e S foi ocasionado pelo aumento nos teores de Ca trocável e de $\mathrm{S}_{-} \mathrm{SO}_{4}{ }^{2-}$ do solo com a sua aplicação.

A produção de grãos de cevada não foi influenciada pelos tratamentos de calagem. A produção média de grãos foi de $1.862,1.713$ e 1.820 kg.ha ${ }^{-1}$, para os tratamentos sem calcário, calcário na superfície e calcário incorporado respectivamente. Esses resultados diferem, substancialmente, dos obtidos por PöTTKER $\mathrm{e}$ BEN (1998) que verificaram, para a mesma cultivar de cevada, acréscimos na produção de grãos de $70 \%$ a $115 \%$, com a calagem na superfície ou com calcário incorporado, em dois solos com diferentes teores de argila (LVd e LVdf). A diferença de resultados pode ser explicada por duas causas principais. A primeira diz respeito aos teores mais elevados de $\mathrm{Al}$ trocável nos solos estudados por PÖTtKer e Ben (1998), em comparação aos deste trabalho. A segunda causa está relacionada ao déficit hídrico observado durante o período de florescimento da cultura, o que não foi

Quadro 3. Concentração de nutrientes nas folhas de cevada em função da calagem e da aplicação de doses de gesso

\begin{tabular}{lccccc}
\hline Tratamento & $\mathrm{P}$ & $\mathrm{K}$ & $\mathrm{Ca}$ & $\mathrm{Mg}$ & $\mathrm{S}$ \\
\cline { 2 - 5 } Calagem & & & $\mathrm{g}^{-1} \mathrm{~kg}^{-1}$ & & \\
Sem calcário & 1,5 & 25,5 & 7,3 & 3,0 & 4,2 \\
Calcário na superfície & 1,9 & 25,1 & 6,8 & 3,3 & 4,7 \\
Calcário incorporado & 1,6 & 26,3 & 7,5 & 3,3 & 4,7 \\
Valor F & $2,79 \mathrm{~ns}$ & $2,04 \mathrm{~ns}$ & $1,13 \mathrm{~ns}$ & $1,49 \mathrm{~ns}$ & $0,92 \mathrm{~ns}$ \\
CV (\%) & 20,9 & 6,3 & 17,2 & 15,2 & 29,4 \\
Gesso, t.ha ${ }^{-1}$ & & & & & \\
0 & 1,6 & 25,1 & 6,1 & 3,4 & 3,5 \\
3 & 1,6 & 24,2 & 6,6 & 3,1 & 4,2 \\
6 & 1,8 & 26,2 & 7,6 & 3,1 & 4,9 \\
9 & 1,6 & 27,0 & 8,4 & 3,2 & 5,5 \\
Efeito & $\mathrm{ns}$ & $\mathrm{L}^{* *}$ & $\mathrm{~L}^{* *}$ & $\mathrm{~ns}$ & $\mathrm{~L}^{* *}$ \\
CV $(\%)$ & 27,0 & 7,3 & 10,0 & 13,2 & 23,9 \\
\hline
\end{tabular}

L: Efeito linear por regressão; ns: Não significativo; **: Significativo a $1 \%$. 
Quadro 4. Absorção de nutrientes pela parte aérea da planta de cevada em função da calagem e da aplicação de doses de gesso

\begin{tabular}{|c|c|c|c|c|c|c|}
\hline Tratamento & $\mathrm{N}$ & $\mathrm{P}$ & $\mathrm{K}$ & $\mathrm{Ca}$ & $\mathrm{Mg}$ & S \\
\hline & & & - & & & \\
\hline \multicolumn{7}{|l|}{ Calagem } \\
\hline Sem calcário & 107,4 & 6,9 & $185,4 \mathrm{~b}$ & 23,2 & 15,6 & 12,9 \\
\hline Calcário na superfície & 128,8 & 8,2 & $207,7 \mathrm{ab}$ & 32,7 & 13,3 & 15,6 \\
\hline Calcário incorporado & 138,9 & 7,2 & 237,6 a & 32,3 & 16,1 & 17,2 \\
\hline Valor F & $6,03 \mathrm{~ns}$ & $4,23 \mathrm{~ns}$ & $7,59^{*}$ & $3,82 \mathrm{~ns}$ & $4,48 \mathrm{~ns}$ & $1,87 \mathrm{~ns}$ \\
\hline CV $(\%)$ & 18,1 & 18,2 & 14,5 & 35,0 & 16,0 & 36,1 \\
\hline \multicolumn{7}{|l|}{ Gesso, t.ha ${ }^{-1}$} \\
\hline 0 & 109,3 & 5,4 & 192,3 & 26,6 & 14,4 & 5,7 \\
\hline 3 & 115,5 & 7,8 & 178,1 & 25,0 & 15,2 & 11,7 \\
\hline 6 & 141,6 & 7,9 & 227,9 & 30,6 & 15,6 & 20,6 \\
\hline 9 & 133,8 & 8,6 & 242,7 & 35,3 & 14,9 & 22,8 \\
\hline Efeito & $\mathrm{L}^{* *}$ & $\mathrm{~L}^{* *}$ & $\mathrm{~L}^{* *}$ & $\mathrm{~L}^{* *}$ & ns & $L^{* *}$ \\
\hline CV (\%) & 18,9 & 29,2 & 17,1 & 24,2 & 23,9 & 27,6 \\
\hline
\end{tabular}

Médias seguidas por letras iguais nas colunas não diferem significativamente pelo teste de Tukey ao nível de 5\%. L: efeito linear por regressão. ns: Não significativo; *: Significativo a 5\%; **: Significativo a 1\%.

relatado por PÖtTKER e BEN (1998). Ressalta-se que o déficit hídrico ocorreu em um período crítico de desenvolvimento da cultura e a seca foi prolongada; houve total ausência de água por precipitação pluvial durante 25 dias após o início do florescimento. Considerando a importância da umidade nos processos de transporte e absorção de nutrientes e que a maior concentração de raízes, com a aplicação de calcário, ocorreu na camada superficial do solo (Quadro 2), esse déficit hídrico prolongado, certamente prejudicou os efeitos benéficos da calagem e limitou a produção de cevada.

Houve aumento significativo na produção de grãos de cevada $\left(\hat{Y}\right.$, em $\left.\mathrm{kg} \cdot \mathrm{ha}^{-1}\right)$, na média de tratamentos de calagem, em função da aplicação de doses de gesso $\left(x\right.$, em t.ha $\left.{ }^{-1}\right)$, sendo a resposta linear $\left(\hat{Y}=1.611,42+41,57 x, \mathrm{R}^{2}=0,78^{* *}\right)$. De acordo com a equação ajustada, o aumento médio na produção, com a maior dose de gesso aplicada $\left(9\right.$ t.ha $\left.^{-1}\right)$, foi aproximadamente de $23 \%$. Esses resultados confirmam o efeito favorável do gesso sobre a produção de grãos (CARVALHO et al., 1986; Sousa e RitCheY, 1986), pela melhoria do ambiente radicular no subsolo, em condições de déficit hídrico.

A análise de correlação entre a produção de grãos de cevada e os atributos da fertilidade do solo, em função da profundidade (Quadro 5), mostrou que o aumento da produção, pela aplicação de doses de gesso, esteve relacionado ao aumento do Ca trocável $(0-20 \mathrm{~cm})$, da relação $\mathrm{Ca} / \mathrm{Mg}(0-40 \mathrm{~cm})$ e do $\mathrm{S}^{-S}{ }_{4}{ }^{2-}$ disponível $(0-60 \mathrm{~cm})$ no solo. É interessante notar que o gesso foi mais eficiente que o calcário, aplicado na superfície ou incorporado, no aumento do Ca trocável em todo o perfil do solo (Quadro 2). Além disso, a aplicação de gesso proporcionou movimentação do $\mathrm{Mg}$ trocável (Figura 1), aumentando a relação $\mathrm{Ca} / \mathrm{Mg}$ no solo. Como a produção de grãos de cevada também correlacionou-se positiva e significativamente com os teores de Ca nas folhas $\left(\mathrm{r}=0,80^{* *}\right)$, é possível inferir que a absorção de Ca pela cevada foi favorecida tanto pelo aumento do Ca trocável como pela relação $\mathrm{Ca} / \mathrm{Mg}$ no solo.

Resposta do milho à aplicação de gesso, em decorrência do fornecimento de enxofre, da melhoria do teor de Ca trocável e do aumento da relação $\mathrm{Ca} / \mathrm{Mg}$ no solo, também foi observada por CAIRES et al. (1999). O mesmo efeito não ocorre na cultura da soja (CARvalho et al., 1986; QuagGio et al., 1993; Oliveira e PAVAN, 1996; CAires et al., 1998). Deve-se considerar que as gramíneas apresentam raízes com capacidade de troca de cátions (CTC radicular) mais baixa que as leguminosas (Rosolem, 1989). Em função disso, as gramíneas seriam mais eficientes na absorção de $\mathrm{K}^{+}$, enquanto as leguminosas, mais eficientes na absorção de $\mathrm{Ca}^{2+} \mathrm{e} \mathrm{Mg}^{2+}$. Essa pode ser uma explicação para as respostas positivas de gramíneas, como o milho e a cevada, à aplicação de gesso, tendo em vista a menor eficiência dessas plantas na absorção de cátions divalentes. A absorção de $\mathrm{Ca}^{2+}$, nesse caso, pode ser favorecida pelo aumento do Ca trocável e da relação $\mathrm{Ca} / \mathrm{Mg}$ no solo. Da mesma forma, a ausência de resposta de leguminosas, como a soja, ao gesso aplicado, 
Quadro 5. Coeficientes de correlação entre a produção de grãos de cevada e os atributos da fertilidade do solo, em função da profundidade

\begin{tabular}{lcccccc}
\hline Profundidade & $\mathrm{pH}\left(\mathrm{CaCl}_{2}\right)$ & $\mathrm{Al}$ trocável & Saturação por $\mathrm{Al}^{3+}$ & Ca trocável & Relação Ca/Mg & ${\mathrm{S}-\mathrm{SO}_{4}{ }^{2-}}^{\mathrm{cm}}$ \\
$\mathrm{cm}$ & & & & & & \\
$0-10$ & $-0,04 \mathrm{~ns}$ & $0,15 \mathrm{~ns}$ & $0,08 \mathrm{~ns}$ & $0,59^{*}$ & $0,85^{* *}$ & $0,93^{* *}$ \\
$10-20$ & $-0,03 \mathrm{~ns}$ & $0,07 \mathrm{~ns}$ & $-0,10 \mathrm{~ns}$ & $0,54^{*}$ & $0,70^{*}$ & $0,88^{*}$ \\
$20-40$ & $0,08 \mathrm{~ns}$ & $-0,15 \mathrm{~ns}$ & $-0,24 \mathrm{~ns}$ & $0,49 \mathrm{~ns}$ & $0,76^{* *}$ & $0,88^{*}$ \\
$40-60$ & $0,22 \mathrm{~ns}$ & $0,11 \mathrm{~ns}$ & $-0,26 \mathrm{~ns}$ & $0,44 \mathrm{~ns}$ & $0,33 \mathrm{~ns}$ & $0,97^{* *}$ \\
\hline
\end{tabular}

ns: Não significativo; *: Significativo a $5 \%$; **: Significativo a $1 \%$.

pode estar relacionada à maior eficiência da cultura na absorção de $\mathrm{Ca}^{2+}$.

Destaca-se, ainda, o efeito positivo do fornecimento do enxofre pelo gesso sobre a produção de grãos de cevada, em solo com teor médio de $10,4 \mathrm{mg} \cdot \mathrm{dm}^{-3}$ de S-SO ${ }_{4}{ }^{2-}$, na camada de $0-20 \mathrm{~cm}$. Esses resultados mostram a importância da melhoria do teor de sulfato no perfil do solo para a produção de grãos, em situações de déficit hídrico no período de florescimento da cultura.

\section{CONCLUSÕES}

1. A densidade, superfície e raio médio de raízes de cevada não foram influenciados pela calagem, na superfície ou incorporada, e aplicação de gesso, embora o gesso tenha proporcionado melhor distribuição relativa do sistema radicular em profundidade, principalmente quando associado à calagem. Em situações de déficit hídrico severo, não houve limitação no crescimento radicular da cevada, em profundidade, para teor de Ca trocável de $6 \mathrm{mmol}_{\mathrm{c}} \cdot \mathrm{dm}^{-3} \mathrm{e}$ saturação por $\mathrm{Al}$ de $35 \%$.

2. A incorporação de calcário em solo ácido melhora a nutrição de $\mathrm{N}$ e $\mathrm{K}$ da cevada, mas quando ocorre estiagem no período de florescimento da cultura, a produção de grãos é limitada e não é influenciada pela correção da acidez por meio da calagem na superfície ou com incorporação.

3. A aplicação de gesso melhora a absorção de $\mathrm{N}$, $\mathrm{P}, \mathrm{K}$, Ca e S pela cevada, em condições de deficiência de água, proporcionando acréscimos na produção de grãos, em decorrência de aumento do Ca trocável, da relação $\mathrm{Ca} / \mathrm{Mg}$ e do $\mathrm{S}_{-} \mathrm{SO}_{4}{ }^{2-}$ disponível no solo.

\section{REFERÊNCIAS BIBLIOGRÁFICAS}

ADAMS, F.; MOORE, B.L. Chemical factors affecting root growth in subsoil horizons of coastal plain soils. Soil Science Society of America Journal, Madison, v.47, p.99102, 1983.

CAIRES, E.F.; BANZATTO, D.A.; FONSECA, A.F. Calagem na superfície em sistema plantio direto. Revista Brasileira de Ciência do Solo, Viçosa, v.24, n.1, p.161-169, 2000.
CAIRES, E.F.; CHUEIRI, W.A.; MADRUGA, E.F.; FIGUEIREDO, A. Alterações de características químicas do solo e resposta da soja ao calcário e gesso aplicados na superfície em sistema de cultivo sem preparo do solo. Revista Brasileira de Ciência do Solo, Viçosa, v.22, n.1, p.27-34, 1998.

CAIRES, E.F.; FONSECA, A.F.; MENDES, J.; CHUEIRI, W.A.; MADRUGA, E.F. Produção de milho, trigo e soja em função das alterações das características químicas do solo pela aplicação de calcário e gesso na superfície, em sistema de plantio direto. Revista Brasileira de Ciência do Solo, Viçosa, v.23, n.2, p.315-327, 1999.

CAIRES, E.F.; ROSOLEM, C.A. Calagem em genótipos de amendoim. Revista Brasileira de Ciência do Solo, Campinas, v.17, p.193-202, 1993.

CAIRES, E.F.; ROSOLEM, C.A. Root growth of peanut cultivars and soil acidity. In: WRIGHT, R.J.; BALIGAR, V.C.; MURRMANN, R.P. (Eds.). Plant-soil interactions at low pH. Dordrecht: Kluwer Academic Publishers, 1991. p.239-243.

CAMARGO, O.A.; RAIJ, B. van. Movimento do gesso em amostras de latossolos com diferentes propriedades eletroquímicas. Revista Brasileira de Ciência do Solo, Campinas, v.13, p.275-280, 1989.

CAMERON, R.S.; RITCHIE, G.S.P.; ROBSON, A.D. Relative toxicities of inorganic aluminum complexes to barley. Soil Science Society of America Journal, Madison, v.50, p.1231-1236, 1986.

CARVALHO, L.J.C.B.; GOMIDE, R.L.; RODRIGUES, G.C.; SOUSA, D.M.G.; FREITAS-JÚNIOR, E. Resposta do milho à aplicação de gesso e déficit hídrico em solos de cerrado. In: SEMINÁRIO SOBRE O USO DE FOSFOGESSO NA AGRICULTURA, 1., 1986, Brasília. Anais... Brasília: EMBRAPA-DDT, 1986. p.61-83.

CLARKSON, D.T. Interactions between aluminum and phosphorus on root surfaces cell wall material. Plant Soil, Dordrecht, v.27, p.347-355, 1967.

FOY, C.D. Tolerance of barley cultivars to an acid, aluminium-toxic subsoil related to mineral element concentrations in their shoots. Journal of Plant Nutrition, New York, v.19, n.10-11, p.1361-1380, 1996. 
FRANCHINI, J.C.; MALAVOLTA, E.; MIYAZAWA, M.; PAVAN, M.A. Alterações químicas em solos ácidos após a aplicação de resíduos vegetais. Revista Brasileira de Ciência do Solo, Viçosa, v.23, n.3, p.533-542, 1999.

HALLMARK, W.B.; BARBER, S.A. Root growth and morphology, nutrient uptake and nutrient status of early grown soybeans as affected by soil P and K. Agronomy Journal, Madison, v.76, p.209-212, 1984.

HOYT, P.B.; TURNER, R.C. Effects of organic materials added to very acid soils on $\mathrm{pH}$, aluminum, exchangeable $\mathrm{NH}_{4}$ and crop yields. Soil Science, Baltimore, v.119, p.227-237, 1975.

MALAVOLTA, E.; VITTI, G.C.; OLIVEIRA, S.A. Avaliação do estado nutricional das plantas: princípios e aplicações. 2.ed. Piracicaba: Associação Brasileira para Pesquisa da Potassa e do Fosfato, 1997. 319p.

McCORMICK, L.H.; BORDEN, F.Y. Phosphate fixation by aluminum in plant roots. Soil Science Society of America Proceedings, Madison, v.36, p.799-807, 1972.

MINELLA, E.; ARIAS, G.; LINHARES, A.G.; SILVA, M.S. Cultivar BR-2: Cultivar de cevada cervejeira resistente à mancha-reticular causada por Pyrenophora teres. Pesquisa Agropecuária Brasileira, Brasília, v.34, n.11, p.21632168, 1999.

MIYAZAWA, M.; PAVAN, M.A.; SANTOS, J.C.F. Effects of addition of crop residues on the leaching of $\mathrm{Ca}$ and $\mathrm{Mg}$ in Oxysols. In: INTERNATIONAL SYMPOSIUM ON PLANT-SOIL INTERACTIONS AT LOW pH, 4., 1996, Belo Horizonte. Abstracts. Belo Horizonte: Sociedade Brasileira de Ciência do Solo/EMBRAPA-CPAC, 1996. p.8.

NOGUEIRA, A.R.A.; MOZETO, A.A. Interações químicas do sulfato e carbonato de cálcio em seis solos paulistas sob vegetação de cerrado. Revista Brasileira de Ciência do Solo, Campinas, v.14, p.1-6, 1990.

OLIVEIRA, E.L.; PAVAN, M.A. Control of soil acidity in no-tillage system for soybean production. Soil \& Tillage Research, Amsterdam, v.38, p.47-57, 1996.

OLMOS, I.L.J.; CAMARGO, M.N. Ocorrência de alumínio tóxico nos solos do Brasil, sua caracterização e distribuição. Ciência e Cultura, São Paulo, v.28, p.171-180, 1976.

PAVAN, M.A.; BLOCH, M.F.; ZEMPULSKI, H.C.; MIYAZAWA, M.; ZOCOLER, D.C. Manual de análise química do solo e controle de qualidade. Londrina: Instituto Agronômico do Paraná, 1992. 38p. (Circular, 76)

PÖTTKER, D.; BEN, J.R. Calagem para uma rotação de culturas no sistema plantio direto. Revista Brasileira de Ciência do Solo, Viçosa, v.22, n.4, p.675-684, 1998.
QUAGGIO, J.A.; RAIJ, B. van; GALLO, P.B.; MASCARENHAS, H.A.A. Respostas da soja à aplicação de calcário e gesso e lixiviação de íons no perfil do solo. Pesquisa Agropecuária Brasileira, Brasília, v.28, n.3, p.375-383, 1993.

RAIJ, B. van. Gesso agrícola na melhoria do ambiente radicular no subsolo. São Paulo: Associação Nacional para Difusão de Adubos e Corretivos Agrícolas, 1988. 88p.

RAIJ, B. van; CANTARELLA, H.; FURLANI, P.R. Efeito, na reação do solo, da absorção de amônio e nitrato pelo sorgo, na presença e na ausência de gesso. Revista Brasileira de Ciência do Solo, Campinas, v.12, p.131-136, 1988.

RITCHEY, K.D.; SILVA, S.E.; COSTA, V.F. Calcium deficiency in clayey B horizons of savannah Oxisols. Soil Science, Baltimore, v.133, p.378-382, 1982.

ROSOLEM, C.A. Interpretação dos teores de bases trocáveis do solo. In: BÜLL, L.T.; ROSOLEM, C.A. (Eds.). Interpretação de análise química de solo e planta para fins de adubação. Botucatu: Fundação de Estudos e Pesquisas Agrícolas e Florestais, 1989. p.97-128.

ROSOLEM, C.A.; BICUDO, S.J.; MARUBAYASHI, O.M. Soybean yield and root growth as affected by lime rate and quality. In: DATE, R.A. (Ed.). Plant-soil interactions at low $\mathrm{pH}$. Dordrecht: Kluwer Academic Publishers, 1995. p.543-547.

ROSOLEM, C.A.; VALE, L.S.R.; GRASSI-FILHO, H.; MORAES, M.H. Sistema radicular e nutrição do milho em função da calagem e da compactação do solo. Revista Brasileira de Ciência do Solo, Campinas, v.18, p.491-497, 1994.

SALET, R.L.; ANGHINONI, I.; FORNARI, T.G.; KRAY, C.H. O alumínio é menos tóxico no sistema plantio direto. In: REUNIÃO SUL-BRASILEIRA DE CIÊNCIA DO SOLO, 1., 1996, Lages. Resumos Expandidos. Lages: Sociedade Brasileira de Ciência do Solo/Núcleo Regional Sul, 1996. p.72-74.

SOUSA, D.M.G.; RITCHEY, K.D. Uso de gesso no solo de cerrado. In: SEMINÁRIO SOBRE O USO DE FOSFOGESSO NA AGRICULTURA, 1., 1986, Brasília. Anais... Brasília: EMBRAPA-DDT, 1986. p.119-144.

SUMNER, M.E. Amelioration of subsoil acidity with minimum disturbance. In: JAYAWARDANE, N.S.; STEWART, B.A. (Eds.). Subsoil management techniques. Athens: Lewis Publishers, 1995. p.147-185.

SYED-OMAR, S.R.; SUMNER, M.E. Effect of gypsum on soil potassium and magnesium status and growth of alfafa. Communication in Soil Science and Plant Analysis, New York, v.22, p.2017-2028, 1991.

TENNANT, D. A test of a modified line intersect method of estimating root length. Journal of Ecology, London, v.63, p.995-1001, 1975. 
VITTI, G.C.; SUZUKI, J.A. A determinação do enxofre - sulfato pelo método turbidimétrico. Jaboticabal: Universidade Estadual de São Paulo, 1978. 13p. (Apostila)
WRIGHT, R.J.; HERN, J.L.; BALIGAR, V.C.; BENNETT, O.L. The effect of surface applied soil amendments on barley root growth in an acid subsoil. Communication in Soil Science and Plant Analysis, New York, v.16, n.2, p.179-192, 1985. 